\title{
Protein JTB
}

National Cancer Institute

\section{Source}

National Cancer Institute. Protein JTB. NCI Thesaurus. Code C29689.

Protein JTB (146 aa, $\sim 16 \mathrm{kDa}$ ) is encoded by the human JTB gene. This protein plays a role in both cytokinesis and apoptosis regulation. 